\title{
Influence of Dispersion on Transport of Tracer through Unsaturated Porous Media
}

\author{
T. Bunsri ${ }^{1}$ M. Sivakumar ${ }^{2}$ and D. Hagare ${ }^{3}$ \\ ${ }^{1}$ National Center of Excellence for Environmental and Hazardous Waste Management (NCE-EHWM), Department of \\ Environmental Engineering, Faculty of Engineering, King Mongkut's University of Technology Thonburi, Bangkok 10140, \\ Thailand \\ ${ }^{2}$ Sustainable Water and Energy Research Group (SWERG), School of Civil, Mining and Environmental Engineering, \\ Faculty of Engineering, University of Wollongong, NSW 2522, Australia \\ ${ }^{3}$ Sterling College, Level 3, 770 George Street, Sydney, NSW 2000, Australia
}

Email: thidarat.bun@kmutt.ac.th

(Received March 13, 2007; accepted September 25, 2007)

\begin{abstract}
The dispersion phenomenon has resulted from the various water flow magnitude and direction in porous media. The dissolved tracer tends to spread due to dispersion and then travel time of tracer through the porous media increases. In unsaturated porous media, dispersion coefficient varies with non-linear Darcy's velocity and the water content. These nonlinear dispersions were observed in both of the laboratory scale sand and soil columns $(20 \mathrm{~cm})$. The unsaturated infiltration column and tracer tests have been used to interpret the relationships between Darcy's velocity and the water content together with the dispersion coefficient. However, the dispersivity coefficient cannot be measured directly; it has to be determined from advection-dispersion equation (ADE), which can be used to model the tracer transport in unsaturated porous media. The model was used to describe the non-linear functions of water contents and dispersivities for both porous media. The simulations have been verified that the dispersion of tracer through soil is higher than that of sand column and also the travel time of tracer through soil is longer than that of sand column. Even though, soil has very low degree of pore velocity, high dispersivity is observed in the simulations. The water content and tracer concentration profiles reveal that the increase of dispersivity induces the increase of flow path distance and the decrease of pore velocity. The maximum dispersivity was observed when the water content of porous media is relatively low; this leadsto the maximum of spreading of tracer.
\end{abstract}

Keywords: advection-dispersion processes, numerical model, pore-scale water flow, unsaturated flow.

\section{NOMENCLATURE}

$\begin{array}{ll}C & \text { tracer concentration; } \mathrm{g} \mathrm{cm}^{-1} \\ D_{H} & \text { hydrodynamic dispersion coefficient; } \mathrm{cm}^{2} \mathrm{~h}^{-1} \\ D_{M} & \text { molecular dispersion coefficient; } \mathrm{cm}^{2} \mathrm{~h}^{-1} \\ D_{z} & \text { dispersion coefficient; } \mathrm{cm}^{2} \mathrm{~h}^{-1} \\ k_{r w} & \text { relative conductivity; }\left(0 \leq k_{r w} \leq 1\right) ; \text { unitless } \\ K_{z z} & \text { saturated hydraulic conductivity; } \mathrm{cm} \mathrm{h}^{-1} \\ K_{z z} k_{r w} & \text { unsaturated hydraulic conductivity; } \mathrm{cm} \mathrm{h}^{-1} \\ m & \text { hydraulic properties coefficient; }\left(1-\frac{1}{n}\right) \text { unitless } \\ M & \text { specific moisture capacity; }(\partial \theta / \partial \psi) ; \mathrm{cm}^{-1} \\ n & \text { hydraulic properties coefficient; unitless } \\ N_{i} & \text { stiffness function; unitless } \\ N_{j} & \text { shape function; unitless }\end{array}$

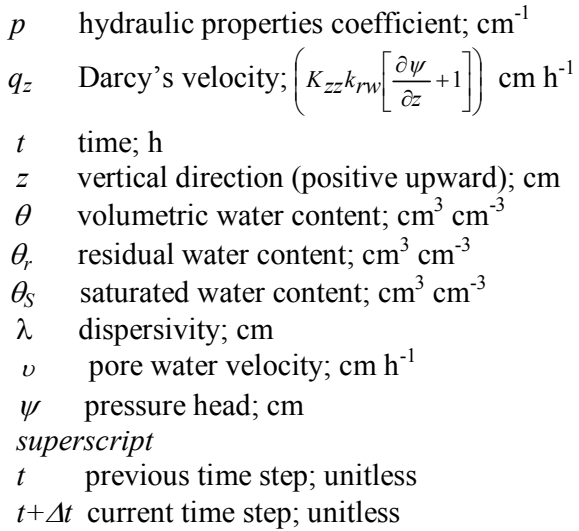

$p \quad$ hydraulic properties coefficient; $\mathrm{cm}^{-1}$

$q_{z} \quad$ Darcy's velocity; $\left(K_{z z} k_{r w}\left[\frac{\partial \psi}{\partial z}+1\right]\right) \mathrm{cm} \mathrm{h}^{-1}$

time; $\mathrm{h}$

vertical direction (positive upward); $\mathrm{cm}$

$\theta \quad$ volumetric water content; $\mathrm{cm}^{3} \mathrm{~cm}^{-3}$

$\theta_{r} \quad$ residual water content; $\mathrm{cm}^{3} \mathrm{~cm}^{-3}$

$\theta_{S}$ saturated water content; $\mathrm{cm}^{3} \mathrm{~cm}^{-3}$

dispersivity; $\mathrm{cm}$

$\psi$ pressure head; $\mathrm{cm}$

$t \quad$ previous time step; unitless
$t+\Delta t$ current time step; unitless 


\section{INTRODUCTION}

The transport processes of contaminants in porous media results from the advection and dispersion of contaminated fluid in such environment. Water moves due to gravitational force and carries many contaminant species. The contaminants tend to spread due to the molecular diffusion and the hydrodynamic dispersion (Gelhar et al. 1992; Nützmann et al. 2002; Toride et al. 2003). The molecular diffusion is driven by the concentration gradient, even though there is a stagnant flow of water (Fetter 1992). The hydrodynamic dispersion occurs because of the heterogeneity of the microscopic velocities inside the soil pores as a result of the complex pore structures (Schnoor 1996). In the saturated porous media, the hydrodynamics dispersion varies with the fully saturated flow velocity. The linear relation between dispersivity and pore velocity is valid. The hydrodynamic dispersion could be estimated from the multiplication between dispersivity and pore velocity (Fetter 1992). On the other hand, the hydrodynamic dispersion coefficients for unsaturated porous media depends upon the pore velocity and moisture content (Nützmann et al. 2002). As the moisture content decreases, the fluctuation flow velocity and the distance of flow paths increases significantly, so the travel time of solute through porous media can be extended (Nützmann et al. 2002; Toride et al. 2003). This paper focuses on the basic principles of water moving due to advection and dispersion through the unsaturated zone and investigates the relationships between moisture content and unsaturated flow velocity together with the dispersivity coefficient. The model calibration was undertaken by comparing the numerical solution and experimental results in both sand and soil infiltration columns.

\section{GOVERNING EQUATIONS}

\subsection{Water movement model}

One dimensional vertical water movement in unsaturated soil can be described using Richard's equation (Ségol, 1993):

$M \frac{\partial \psi}{\partial t}=\frac{\partial}{\partial z}\left[K_{z z} k_{r w}\left(\frac{\partial \psi}{\partial z}+1\right)\right]$

The term $\frac{\partial}{\partial z}\left[K_{z z} k_{r w}\left(\frac{\partial \psi}{\partial z}+1\right)\right]$ refers to Darcy's velocity in unsaturated soil condition $\left(q_{z}\right)$. Water movement equation contains three unknown variables including of $M, k_{r w}$ and $q_{z}$. There are additional relations, which are necessary to support the model calculation.

The hydraulic properties including $M$ and $K_{z z} k_{r w}$ are obtained by adopting van Genuchten et al. (1980) model to define the characteristics of water retention, as follows (Fetter 1992):

$$
\theta=\theta_{r}+\frac{\theta_{S}-\theta_{r}}{\left[1+(p \cdot|\psi|)^{n}\right]^{m}}
$$

$$
K_{z z} k_{r w}=K_{z z} \frac{\left[1-(p \cdot|\psi|)^{n-1}\left[1+(p \cdot|\psi|)^{n}\right]^{-m}\right]^{2}}{\left[1+(p \cdot|\psi|)^{n}\right]^{m / 2}}
$$

\subsection{Solute transport model}

One-dimensional tracer transport in unsaturated soil can be explained using advection dispersion equation (ADE) as (Fetter 1992; Schnoor 1996):

$$
\frac{\partial C}{\partial t}=D_{z} \frac{\partial^{2} C}{\partial z^{2}}-q_{z} \frac{\partial C}{\partial z}
$$

The microscopic velocity distribution can be regarded as mechanical dispersion coefficient, which is influenced by Darcy's velocity (Fetter 1992; van Genuchten and Wierenga 1986):

$$
\begin{aligned}
& v=\frac{q_{z}}{\theta} \\
& D_{H}=\lambda \cdot v
\end{aligned}
$$

The dispersion coefficient coupling mechanical and molecular diffusion, the equation was given as (van Genuchten and Wierenga1986; Fetter 1992):

$$
D_{z}=\lambda v+D_{M}
$$

\section{DEVELOPMENT OF NUMERICAL MODELS}

Richards' equation and ADE can be solved numerically with the Galerkin technique (weight residual method) and the systematic algebraic matrices are obtained from the finite element method (Huyakorn and Pinder 1983; Huyakorn et al. 1984). The numerical solutions for water movement and tracer transport models were simplified as follows.

Water movement model:

$$
\left[A_{i j}\right] \psi_{j}+\left[B_{i j}\right] \frac{\partial \psi_{j}}{\partial t}=\left\{E_{i}\right\}
$$

where

$$
\begin{aligned}
& {\left[A_{i j}\right]=\sum_{e} \int_{z=0}^{z=L} K_{z z} k_{r w}\left(\frac{\partial N_{i}}{\partial z} \frac{\partial N_{j}}{\partial z}\right) d z ;\left[B_{i j}\right]=\sum_{e} \int_{z=0}^{z=L} N_{i} N_{j} M d z} \\
& \left\{E_{i}\right\}=\left.N_{i} K_{z z} k_{r w}\left(\frac{\partial \psi}{\partial z}+1\right)\right|_{z=0} ^{z=L}-\sum_{e}^{z=L} \int_{z=0}^{z=L} K_{z z} k_{r w} \frac{\partial N_{i}}{\partial z} d z
\end{aligned}
$$

Solute transport model:

$$
\left.\left\{P_{i j}\right]+\left[Q_{i j}\right]\right\} C_{j}+\left[Q_{i j}\right] \frac{\partial C_{j}}{\partial t}=\left\{S_{i}\right\}
$$

where

$$
\begin{aligned}
& {\left[P_{i j}\right]=\sum_{e} \int_{z=0}^{z=L}\left(D_{z} \frac{\partial N_{i}}{\partial z} \frac{\partial N_{j}}{\partial z}+N_{i} \frac{\partial N_{j}}{\partial z} q_{z}\right) d z} \\
& {\left[Q_{i j}\right]=\sum_{e} \int_{z=0}^{z=L} N_{i} N_{j} \theta d z ;\left\{S_{i}\right\}=\left.N_{i} D_{z}\left(\frac{\partial C}{\partial z}\right)\right|_{z=0} ^{z=L}}
\end{aligned}
$$


By the nature, the finite element method might give the underestimated pressure head solutions, particularly near the infiltration front. The oscillations near the infiltration front brought the mass lumping in finite element approximation. Thus, the finite element approach might generate an inaccurate prediction for movement of tracer due to advection-dispersion. The mass lumping was necessary to eliminate problems when using mass-conserving schemes (Hills et al. 1989). The finite-element mass-balance (MB) measure is:

$$
M B\left(t^{n+1}\right)=\frac{\sum_{i=1}^{E-1}\left(\theta_{i}^{n+1}-\theta_{i}^{0}\right) \Delta z+\left(\theta_{0}^{n+1}-\theta_{0}^{0}\right) \frac{\Delta z}{2}+\left(\theta_{E}^{n+1}-\theta_{E}^{0}\right) \frac{\Delta z}{2}}{\sum_{k=1}^{n+1}\left(q_{0}^{k}-q_{L}^{k}\right) \Delta t}
$$

where $q_{o}$ and $q_{L}$ are the boundary fluxes associated with node $z_{O}$ and $z_{L}$, respectively. $\theta^{0}$ and $\theta^{n+1}$ are the approximate value at an initial and the latest estimated values of $\theta$, respectively. Subscript, $E, O$ and $i$ denote the value of $\theta$ at the latest, an initial and the calculating elements, respectively.

The stiffness algebraic system was formed with linear Lagrange function (Huyakorn and Pinder 1983). These numerical solutions were iterated with the single Picard iteration procedure and given as follows (Ségol 1993).

Water movement model:

$$
\begin{aligned}
& \left(\frac{1}{2}\left[A_{i j}\right]^{t}+\frac{1}{\Delta t}\left[B_{i j}\right]^{t}\right)\left(\{\psi\}^{t+\Delta t}-\{\psi\}^{t}\right) \\
& =\left\{E_{i}\right\}-\left[A_{i j}\right]^{t}\{\psi\}
\end{aligned}
$$

Solute transport model:

$$
\begin{aligned}
& \left\{\left(\frac{1}{2}\left(\left[P_{i j}\right]^{t}+\left[Q_{i j}\right]^{t}\right)\right)+\frac{1}{\Delta t}\left[Q_{i j}\right]^{t}\right\}\left\{\{C\}^{t+\Delta t}-\{C\}^{t}\right) \\
& =\left\{S_{i}\right\}-\left(\left[P_{i j}\right]^{t}+\left[Q_{i j}\right]^{t}\right)\{C\}^{t}
\end{aligned}
$$

The computational codes for solutions of water movement and solute transport were prepared using MATLAB. The numerical solution is compared with the experimental results to determine the accuracy of the numerical procedure.

\section{MATERIALS AND METHODS}

Water movement was measured using laboratory scale experiments, a schematic of which is shown in Fig. 1. Medium grained samples of sand from river stock were sieved, with particle size ranging from 250 to $500 \mu \mathrm{m}$. The effective particle size of medium sand; $d_{10}$ is $250 \mu \mathrm{m}$ and the uniformity coefficient $\left(\mathrm{d}_{60} / \mathrm{d}_{10}\right)$ is 2.00 . The soil sample was collected from topsoil behind building 4-Engineering at the University of Wollongong, Australia. Soil sample was kept air dried for one week. All coarse impurities were removed and when sieved, the soil particle sizes were found to be less than $2.00 \mathrm{~mm}$. The infiltration column was fabricated from a $6.59 \mathrm{~cm}$ (inner diameter) x $30 \mathrm{~cm}$ long plexi-glass tube. Medium grain sand and topsoil samples were packed with respect to their actual field bulk densities ( sand $=1.8 \mathrm{~g} / \mathrm{cm}^{3}$ and soil $=1.25 \mathrm{~g} / \mathrm{cm}^{3}$ ).

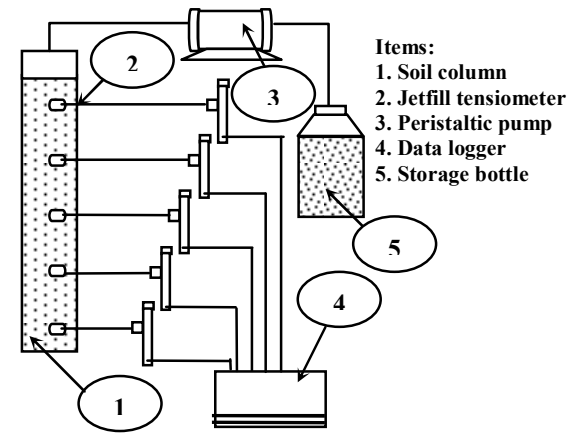

Fig. 1. Column set up.

The hydraulic properties of the sand and soil were determined by packing the column to a depth of $5 \mathrm{~cm}$ where the thin layer of these samples could be assumed as homogenous. Water retention tests for sand and soil were conducted according to the dynamic method (Klute 1986). The infiltration experiment was fed with Wollongong city tap water to produce varying moisture contents. The hydraulic pressure head was recorded using a tensiometer (Jet-fill tensiometer model 2100F) placed $2.5 \mathrm{~cm}$ deep in the middle of the column. All the samples of sand and soil were removed and the water content was analysed immediately. The water content was determined using the gravimetric method (AS 1289.2.1.1-1992; Rayment and Higginson 1992). In addition to the above experiments an infiltration test on a $20 \mathrm{~cm}$ soil column was carried out to observe the movement of waters. Five jet-fill tensiometers were installed $2.5,6.5,10,14$ and $17.5 \mathrm{~cm}$ above the column base. Tap water was fed at a rate of 66.1 and 7.18 $\mathrm{cm}^{3} / \mathrm{h}$, respectively into the sand and soil columns and the water content was analysed at $4 \mathrm{~cm}$ intervals.

For the tracer test, sodium chloride tracer solution with the concentrations of 200 and $500 \mathrm{mg} / \mathrm{L}$ of were applied instead of water, to sand and soil column, respectively. Chloride concentration was examined with electrical conductivity (EC 1:5 soil water extract) (Rayment and Higginson 1992) for every $4 \mathrm{~cm}$ interval.

The sand and soil characteristics were examined according to the Australian Standards Methods for soil testing (AS Standards 1289 1992). The testing was performed at least five times for each parameter and the average values of the sand and soil parameters are given in Table 1 .

\section{RESULTS AND DISCUSSIONS}

\subsection{Hydraulic properties coefficients}

The water characteristic curve was prepared from the plot of pressure head against volumetric moisture content. The data obtained were fitted using van Genuchten's hydraulic properties model (Fetter 1992). The sand and soil water retention curves are given in Fig. 2(a) and 2(b), respectively. 
T. Bunsri et al. / JAFM , Vol. 1, No. 2, pp. 37-44, 2008.

Table 1 Characteristics of dry sand and soil

\begin{tabular}{|l|c|c|}
\hline \multirow{2}{*}{ Parameters } & \multicolumn{2}{|c|}{ Values } \\
\cline { 2 - 3 } & Sand & Topsoil \\
\hline Particle size analysis & 100 & 37.51 \\
Sand (\%) & 0 & 43.79 \\
Silt (\%) & 0 & 18.70 \\
Clay (\%) & Sand & Loam \\
Textural Classification & & \\
Saturated hydraulic & 6.45 & 0.662 \\
conductivity; $\mathrm{K}_{\mathrm{zz}}(\mathrm{cm} / \mathrm{h})$ & 2.65 & 2.55 \\
Specific gravity & 1.79 & 1.28 \\
Bulk density (g/cm $\left.{ }^{3}\right)$ & 0.49 & 0.74 \\
Void ratio & 0.12 & 5.00 \\
Moisture content (\%) & 0.002 & 0.129 \\
EC (1:5) (mhos/cm) & 0.058 & 0.783 \\
Sodium ion (meq/100 g soil) & & \\
& & \\
\hline
\end{tabular}
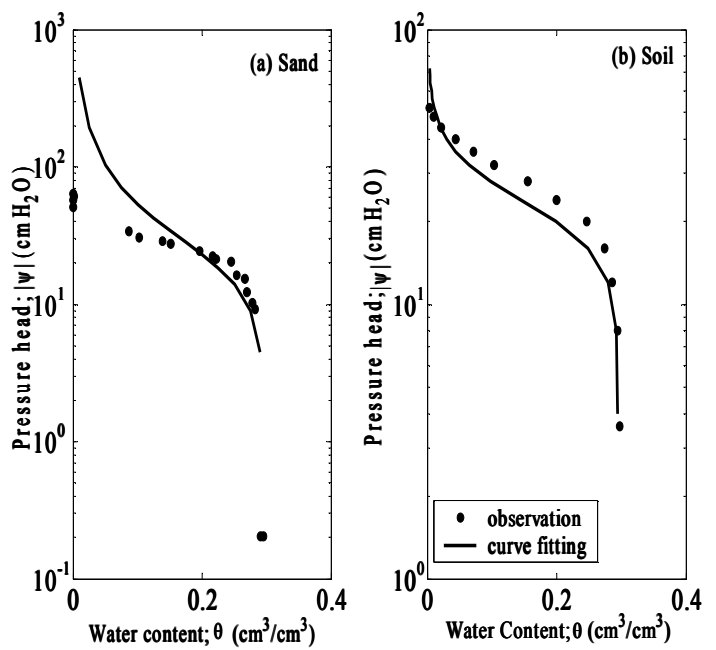

Fig. 2. Observed and fitted water retention curves.

The coefficients of sand and soil hydraulic properties are presented in Table 2. These coefficients were found to be in the acceptable range. For sand, the equations did not fit the observation data well when sand was relatively dry $\left(\theta<0.1 \mathrm{~cm}^{3} / \mathrm{cm}^{3}\right)$. This error might have been generated in the measurements. The jet filled tensiometer was sensitive to presence of bubbles; if sand was relatively dry, air bubble could pass through a porous tip of the tensiometer. These bubbles could potentially disturb the reading signal (Fredlune and Rahardjo 1940). On the other hand, a good fit was obtained in the soil column. This might relate to the composition of the soil that was a mixture of clay, silt and sand. The fine particles of clay and silt could resist the movement of pore water for a long time. The soil column was always relatively wet and the bubble could not reach the porous stone tip, so the reading signal was highly accurate.

\subsection{Simulation of water movement}

The empirical coefficients shown in Table 2 were used for subsequent calculations of water movement. The computationl code developed was applied to the $20 \mathrm{~cm}$ infiltration tests.
Table 2 Empirical coefficients of the sand and soil hydraulic properties

\begin{tabular}{|l|c|c|}
\hline \multicolumn{1}{|c|}{$\begin{array}{c}\text { Hydraulic } \\
\text { parameters }\end{array}$} & $\begin{array}{c}\text { Carsel et al. } \\
(\mathbf{1 9 8 8})\end{array}$ & $\begin{array}{c}\text { This present } \\
\text { study }\end{array}$ \\
\hline Sand & & \\
$\theta_{s}$ & 0.43 & 0.30 \\
$\theta_{r}$ & 0.045 & 0.07 \\
$p(1 / \mathrm{cm})$ & 0.145 & 0.045 \\
$n$ & 2.68 & 2.16 \\
$m$ & 0.627 & 0.538 \\
Soil & & \\
$\theta_{s}$ & 0.43 & 0.42 \\
$\theta_{r}$ & 0.078 & 0.040 \\
$p(1 / \mathrm{cm})$ & 0.036 & 0.025 \\
$n$ & 1.56 & 1.67 \\
$m$ & 0.359 & 0.403 \\
\hline
\end{tabular}

For a free drainage condition, the pressure head on the upper boundary depends on the influent feed rate and the lower boundary condition will have constant pressure head. Although the difference between the measured and simulated pressure heads may occur near the infiltration fronts, the solutions is greatly improved by using massconserving schemes. The influence of the time and space increment is virtually eliminated by using the dense grid $(\Delta z=0.5 \mathrm{~cm})$ and a small time interval $(\Delta t=1 / 12 \mathrm{~min}$ for sand column and $\Delta t=1 / 24$ min for soil column). The input parameters of the sand and soil textural infiltration columns are presented in Table 3.

Table 3 Input parameters for laboratory scale sand and soil column test

\begin{tabular}{|l|l|}
\hline \multicolumn{1}{|c|}{ Parameters } & \multicolumn{1}{c|}{ Values } \\
\hline $\begin{array}{l}\text { Domain } \\
\text { Hydraulic properties } \\
\text { function }\end{array}$ & $\begin{array}{l}\text { Column with depth of 20 cm. } \\
\text { van Genuchten coefficients were } \\
\text { provided in Table 2 }\end{array}$ \\
$\begin{array}{l}\text { Initial and boundaries } \\
\text { conditions: } \\
\text { Sand column }\end{array}$ & $\begin{array}{l}\text { Initial pressure head was }-125 \\
\text { cm, upper and lower boundary } \\
\text { conditions were based on the real } \\
\text { time pressure head measuring } \\
\text { data. } \\
\text { Initial pressure head was -624 } \\
\text { cm, upper and lower boundary } \\
\text { conditions were based on the real } \\
\text { time pressure head measuring } \\
\text { data. } \\
720 \text { (sand column) } 1440 \text { (soil } \\
\text { Soil column } \\
\text { column) } \\
0.5 \mathrm{~cm}\end{array}$ \\
\end{tabular}

Simulated pressure head profiles in sand and soil infiltration columns are given in Fig. 3. It was found that sand reached close to equilibrium of flow within 5 hours and however for the soil, it took 3 days. The movement of a sharp front is readily seen in soil rather than in sand. The different pressure head between the upper and lower boundaries causes a gradient in the pressure head that is higher in soil than in sand. Thus the retention time of water in soil is longer than in sand. The wetting sharp front could not obviously be found in sand column 
because the water moved through the sand very quickly and very slowly through the soil. So the uniform horizontal wetting zone could be clearly seen in soil column. The pressure behind the wetting front on the top portion of the column and the pressure head of saturated sand and soil were -12.5 and $-0.05 \mathrm{cmH}_{2} \mathrm{O}$, respectively. This statement suggests that equilibrium between tension and gravity was more rapid in sand than in soil.

The unsaturated water movement model could not only estimate the pressure head profiles but it could also predict the moisture content profiles obtained by the water retention coefficients. These simulations were undertaken at $0.5,1,2$ and 3 hours for the sand while for the soil at 8,24 and 52 hours. The different time intervals were justified in accordance with the different feed rates used. This is further confirmed when comparing the moisture content profiles in sand and soil columns as shown in Fig. 4. The travel time of water through the laboratory scale sand and soil columns were 5-6 and 64-66 hours, respectively.
When combines fine space and time discritisation as well as reducing the mass lumping, the good agreement between the laboratory and observation results were found in all experiments. The ability of the water movement model to reliably predict the observed data is clearly shown both visually and by the relatively high correlation calculated by the residual square $\left(\mathrm{R}^{2}\right)$. Although small difference between observation and simulation persists at some intervals, the consensus solutions were governed. The values of $\mathrm{R}^{2}$ were much higher in soil than sand. This relates to the coefficients of hydraulic parameters presented previously. The pressure head in sand was precisely detected, if it was lower than $-30 \mathrm{cmH}_{2} \mathrm{O}$. However, the measured pressure head was sometimes out of the precision range. The simulations are able to predict well both the hydraulic pressure head and moisture content data with a high correlation coefficient. The hydraulic properties model could be an alternative tool which could act as a conversion between these two parameters.
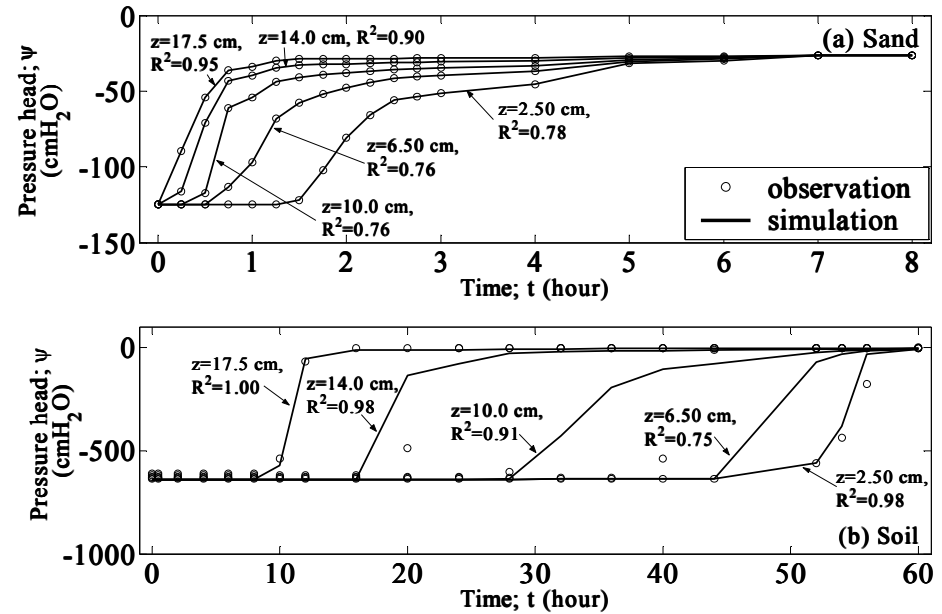

Fig. 3. Elevated pressure head versus time for soil and sand unsaturated soil columns.
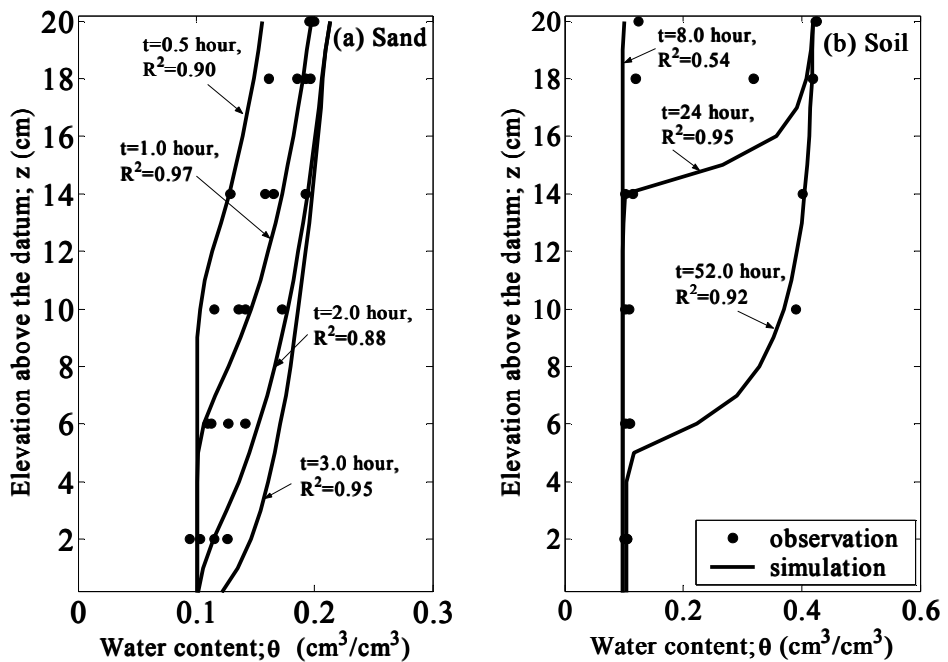

Fig. 4. Volumetric water content profiles in sand and soil infiltration columns. 
Furthermore, this model could calculate the average nodal Darcy's velocities according to the results of the nodal pressure head simulation. Darcy's velocities calculated in sand and soil infiltration columns are given in Table 4.

Table 4 Calculation of Darcy's velocity

\begin{tabular}{|c|c|c|c|}
\hline \multicolumn{2}{|c|}{ Sand infiltration column } & \multicolumn{2}{c|}{ Soil infiltration column } \\
\hline Time (hour) & $\begin{array}{c}\text { Darcy's } \\
\text { velocity } \\
\text { (cm/h) }\end{array}$ & Time (hour) & $\begin{array}{c}\text { Darcy's } \\
\text { velocity } \\
\text { (cm/h) }\end{array}$ \\
\hline 0.5 & $-6.40 \times 10^{-3}$ & 8 & $-1.08 \times 10^{-8}$ \\
1.0 & $-31.6 \times 10^{-3}$ & 16 & $-6.28 \times 10^{-3}$ \\
2.0 & $-80.1 \times 10^{-3}$ & 24 & $-7.48 \times 10^{-3}$ \\
3.0 & $-122 \times 10^{-3}$ & 52 & $-51.7 \times 10^{-3}$ \\
\hline
\end{tabular}

These results further confirm that water could flow through the sand infiltration zone faster than the soil percolation zone. Darcy's velocities calculated along these periods in sand and soil samples are slower than the saturated conductivity $\left(K_{z z}\right)$. This statement reflects the nature of gravitational flow of water feeding through these unsaturated infiltration columns (Warrick et al. 1991). According to the calculated Darcy's velocities for both sand and soil, they have increased over time. Water feeds slowly through the dried packed sand in the first half an hour due to the effect of absorption. The velocities increase significantly from 0.5 to 1 hour when the sand becomes moist, which then increase steadily at 2 and 3 hours. This phenomenon is also seen in the soil. Darcy's velocity after 8 hours was extremely slow because the water is absorbed and stored in the pores. Then Darcy's velocities increase dramatically at 16 hours of feeding, stays relatively steady at 24 hours until they increase again after 52 hours. The phenomenon can be explained by "the ink bottle effect". The water could be retarded in porous media. for a while and the moisture content increases; this is called the wetting stage. This accumulated water could be transmitted when the tension was out of balance with the gravitational force, which is called the "draining stage" (Cullen and Everett 1995). As the water content increases the hydraulic pressure gradient and Darcy's velocity decreases. Dry soil resulted in a high-pressure gradient when compared to wet soil, the water flows through relatively dry soil more quickly than the relatively wet soil (Wierenga 1995).

\subsection{Simulation of solute transport}

The solute transport model was applied to describe the $\mathrm{NaCl}$ tracer concentration profiles observed from sand and soil columns. The input parameters used for the solute transport model are summarised in Table 5. A dense grid $(d z=0.25 \mathrm{~cm})$ and a small time increment $(\Delta t=5 / 106 \mathrm{~min})$ were applied to this simulation. These time and space discritisations were also applied to calculate the nodal moisture content, Darcy's and pore velocities presented in the solute transport model.

The tracer moves through the sand column very quickly, it reaches to the elevations of 16,10 and $2 \mathrm{~cm}$, within, 2 and 3 hours, respectively. The dispersion coefficients, $D_{z}$ are in the range of $0.03-0.83 \mathrm{~cm}^{2} / \mathrm{h}$.
Table 5 Input parameters for tracer transport model

\begin{tabular}{l|l}
\hline \multicolumn{1}{c|}{ Parameters } & \multicolumn{1}{c}{ Values } \\
\hline Domains & Column with depth of $20 \mathrm{~cm}$. \\
NaCl conc. & 200 mg/L (sand ) or $500 \mathrm{mg} / \mathrm{L}$ (soil) \\
$q_{z}$ and $\theta$ & Direct load from Richard's \\
& Equation. \\
$\mathrm{D}_{\mathrm{M}}$ & $0.04788 \mathrm{~cm}^{2} / \mathrm{h}$ \\
Fraction for $\mathrm{D}_{\mathrm{M}}$ & $0.6($ sand) or 0.4 (soil) \\
Boundary & Concentrations at the upper \\
conditions & boundary are 200 (sand) or 500 \\
& (soil) mg/L and at the lower \\
& boundary is 0 mg/L. The initial \\
& concentrations are 200 (sand) or 500 \\
Time domain & (soil) mg/L. \\
No. of time steps; $n t$ & 4 (sand) or 72 hours (soil) \\
Nodal spacing; $d z$ & $1272 \mathrm{steps}$ per hour \\
& $0.25 \mathrm{~cm}$ \\
\hline
\end{tabular}

In addition, the tracer moves very slowly in soil column, it reaches the elevations of $17.5,2.5$ and $5.0 \mathrm{~cm}$, within 8,24 and 56 hours, respectively. The values of $D_{z}$ vary widely from 0.01 to $0.2 \mathrm{~cm}^{2} / \mathrm{h}$. The estimated tracer travel times in a laboratory scale sand and soil columns are approximately 6 and 80 hours, respectively. By comparison, the tracer travel times in sand and soil columns are 1 and 14 hours longer than the ones estimated using water movement model. Coincidently, the tracer concentration profiles appear the same trend as the ones observed from moisture content profiles. This implies that dispersion may not depend only on Darcy's velocity but also on soil water content. The $\mathrm{NaCl}$ tracer might be carried by the flow of water due to the gravitational force. As the water content of the infiltration column increases the concentration of $\mathrm{NaCl}$ tracer increases. The high values of $\mathrm{R}^{2}$ reveal that the simulations in both of sand and soil columns are close to the observations. This implies that the solute transport model could reasonably estimate the dispersion transport of tracer.

The $v-\theta$ relationships of the sand and soil columns are presented in Fig. 6. The unit gradient flow is found, when the pore velocity achieves uniform water content (Toride et al. 2003). The unit gradients flow in sand and soil columns are found at the pore velocity of $0.01-0.8$ and $0.01-0.2$ $\mathrm{cm} / \mathrm{h}$, respectively. The dispersivity; $\lambda$ is estimated as a function of pore velocity at the unit gradient flow, the results are presented in Fig. 7. The dispersivity of relatively wet column increases non-linearly over water content. The maximum dispersivity occurs when the porous media are relatively wet. The maximum dispersivities; $\lambda_{\max }$ of sand and soil are 1.13 and $1.35 \mathrm{~cm}$, at the maximum water contents; $\theta_{\max }$ of 0.13 and $0.20 \mathrm{~cm}^{3} / \mathrm{cm}^{3}$, respectively. The values of $\lambda_{\max }$ and $\theta_{\max }$ of sand reported by Toride et al. (2003) are $0.97 \mathrm{~cm}$ and $0.13 \mathrm{~cm}^{3} / \mathrm{cm}^{3}$, respectively. By comparison, at the same value of $\theta_{\max }$, the values of $\lambda_{\max }$ presented in this experiment and Toride et al. (2003)'s experiment are not much difference. The value of $\lambda_{\max }$ in sand is lower than soil column. This indicates that the finer porous media, the higher dispersion and dispersivity. When the dispersivity increases, the flow path becomes more tortuous and longer, and then the tracer 
travel time might be extended. The high dispersion could spread the tracer widely as shown in soil column. The value of $\theta_{\max }$ in sand was also lower than soil column. This implies that the tracer can widely disperse along the pores in the relatively wet rather than the relatively dry media.
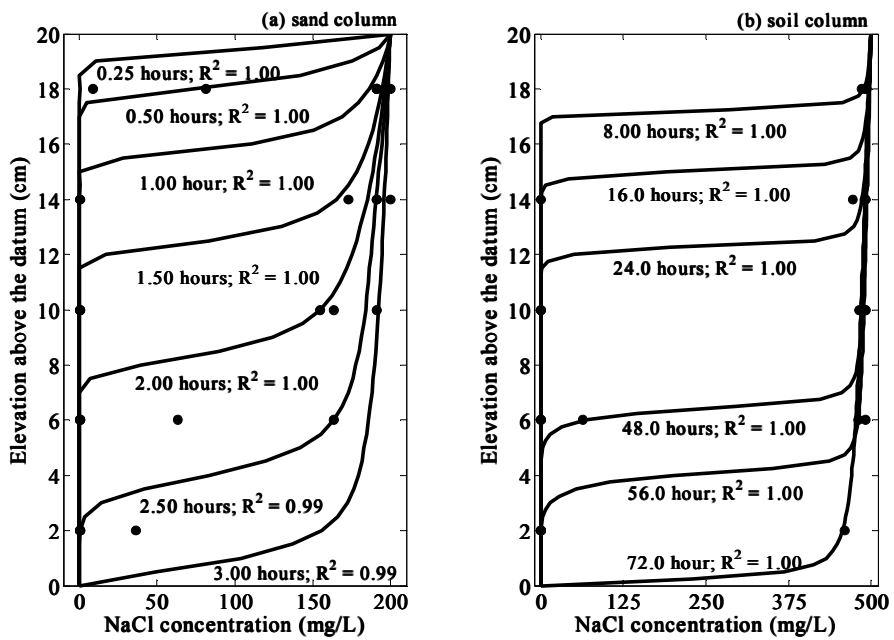

Fig. 5. Tracer concentration profiles in sand and soil columns.
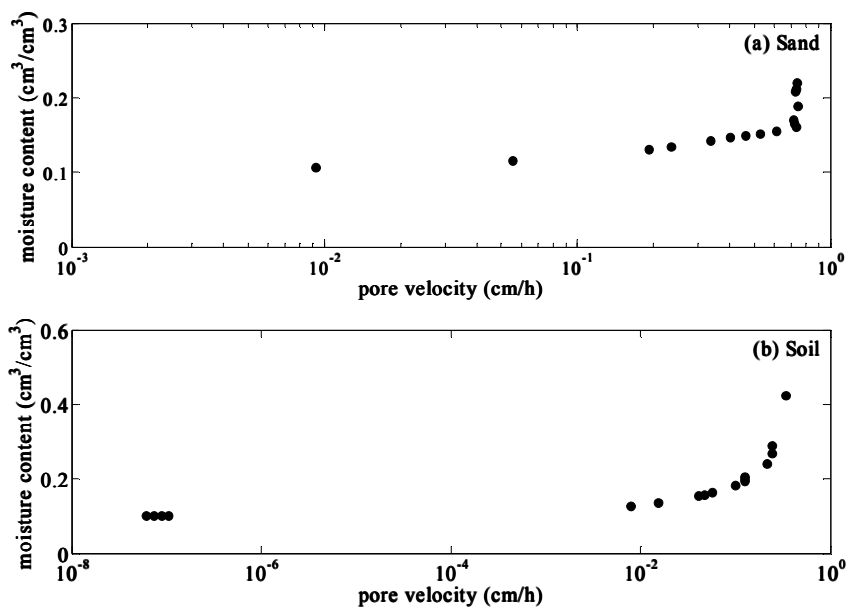

Fig. 6. Relation between dispersivity and pore velocity.

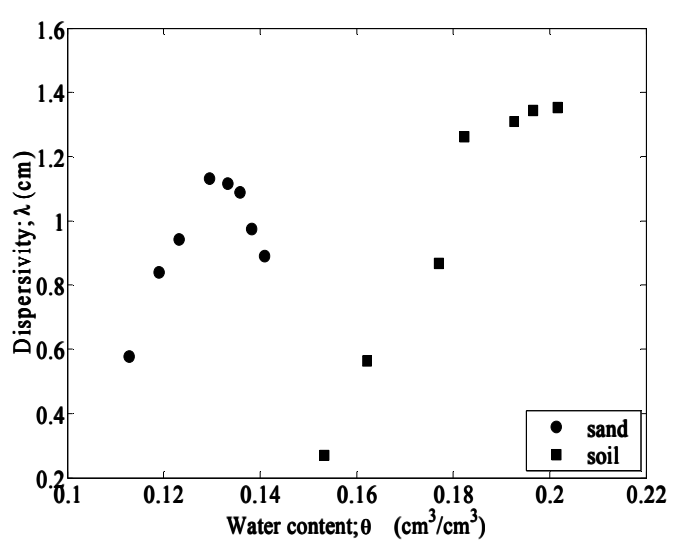

Fig.7. Dispersivity versus volumetric water content for unsaturated sand and soil columns.

\section{CONCLUSION}

The infiltration experiments on sand and soil were investigated to calibrate water movement and tracer transport in both sand and soil infiltration columns. The simulations generated agreed with the free drainage infiltration experimental data. The advection and dispersion play a significant role in the movement of water and tracer. Water movement in unsaturated porous media could be described by Richards' equation. Using van Genuchten hydraulic properties model, one could effectively determine the ideal hydraulic parameters. Tracer transport in unsaturated porous media could be described using the advection-dispersion equation. Water movement and tracer transport models were solved numerically using Galerkin's finite element method (FEM). Non-linear terms were handled with a single 
T. Bunsri et al. / JAFM, Vol. 1, No. 2, pp. 37-44, 2008.

Picard's iteration technique. The developed numerical model was coded with the MATLAB programme. It is concluded that the computational procedure developed provides an easier method for calculating the advection and dispersion movement of water and tracer in unsaturated porous media. During water flow in a porous media, the dissolved tracer tends to spread because of the dispersion, which relates the dispersivity and pore velocity. The simulations suggest that the dispersivity of the unsaturated is higher than the fully saturated porous media. As the water content of porous media decreases, Darcy's and pore velocities also decrease, however, the tortuosity of microscopic flow path increases. This could retard the transport of tracer and extend the tracer travel time. By comparison, the dispersivity of sand is lower than soil, this is because of the lower degree of water content in unsaturated sand.

\section{ACKNOWLEDGEMENTS}

The research facilities provided by the University of Wollongong-Environmental engineering laboratory and the Sustainable Water and Energy Research Group are acknowledged. Funding support was also provided through a PhD scholarship to T. Bunsri by National Research Centre for Environmental and Hazardous Waste Management (NRC-EHWM), and King Mongkut's University of Technology Thonburi, Bangkok, Thailand.

\section{REFERENCES}

Australian Standard (1992). Methods of testing soils for engineering proposes, Methods 2.1.1: soil moisture content tests-Determination of the moisture content of a soil- oven drying method, AS 1289.2.1.1-1992.

Bauters, T.W. J., D. A. DiCarlo, T. S. Steenhuis and J.Y. Parlange (1998). Preferential flow in water-repellent sands. Soil Science Society of America Journal 62 1185-1190.

Cullen, S. J. and L. G. Everett (1995). Estimating the storage capacity of the vadose zone. In L.G. Wilson et al. (Eds.), Handbook of vadose zone characterization \& monitoring, Florida, USA: CRC Press, Inc..

Carsel, R. F. and R. S. Parrish (1988). Developing joint probability distributions of soil-water retention characteristics. Water Resources Research 24(5), 755769.

Fetter, C.W. (1992). Contaminant Hydrology. New York, USA: Macmillan Publishing Company.

Fredlune, D. G. and H. Rahardjo (1940). Soil mechanics for unsaturated soils. New York, USA: John Wiley \& Sons, Inc.

Gelhar, L.W., C. Welty, and K.R. Rehfeldt (1992). A critical review of data on field scale dispersion in aquifers. Water Resources Research 28(7), 1955-1974.

Hills, R.G., I. Porro, D.B. Hudson and P.J. Wierenga (1989). Modeling one-dimensional infiltration into very dry soils, 1 . Model development and evaluation. Water Resources Research 25(6), 1259-1269.
Huyakorn, P.S. and G.F. Pinder (1983). Computational methods in subsurface flow. New York, USA: Academic Press.

Huyakorn, P. S., S. D. Thomas and B.M. Thompson (1984). Technique for making finite element competitive in modeling flow in variably saturated porous media. Water Resources Research 20(8), 10991115.

Klute, A. (1986). Water retention: laboratory methods, in Method of Soil Analysis. In A. Klute et al. (Eds.), Part 1 Physical and Mineralogical Methods, Agronomy, pp 635-662.

Nützmann, G., S. Maciejewski and K. Joswig (2002). Estimation of water saturation dependence of dispersion in unsaturated porous media: experiment and modeling analysis. Advance Water Resources 25, 565-576.

Rayment, G. E. and F. R. Higginson (1992). Australian Laboratory Handbook of Soil and Water Chemical Methods. Melbourne, AUS: Inkata Press.

Schnoor, J. L. (1996). Environmental Modelling: fate and transport of pollutants in water, air and soil. New York, USA.: A Wiley Interscience Publication.

Ségol, G. (1993). Classical groundwater simulations: Proving and improving numerical models. New Jersey, USA: PTR Prentice Hall.

Toride, N., M. Inoue and F.J. Leij (2003). Hydrodynamic dispersion in unsaturated dune sand. Soil Science Society of America Journal 63, 703712.

van Genuchten, M.Th. (1980). A closed-form equation for predicting the hydraulic conductivity of unsaturated soils. Soil Science Society America Journal 44, 892-898.

van Genuchten, M.Th. and P. J. Wierenga (1986). Solute dispersion coefficients and retardation factors. In A. Klute et al. (Eds.), Method of soil analysis, Part 1 Physical and mineralogical methods, Agronomy, pp.1025-1054.

Warrick, A.W. (1991). Numerical approximations of Darcian flow through unsaturated soil. Water Resources Reserach, 27(6), 1215-1222.

Wierenga, P. J. (1995). Water and solute transport and storage, In L.G. Wilson et al. (Eds.), Handbook of vadose zone characterization \& monitoring, Florida: USA, CRC Press, Inc. 